\title{
Time Value and Individual Investment
}

\author{
Zeyan Zhu', a Xinyuan Yu ${ }^{2,}{ }^{* b}$ and Ying Zhang ${ }^{2, c}$ \\ ${ }^{1,2}$ School of Business Administration , Hohai University, Changzhou 213000, China \\ A15161167323@163.com,*Corresponding author \\ Email: byuxinyuan97@sina.com, 543988398yuki@163.com
}

Keywords: time value,individual investment,real estate,stocks,MMF.

\begin{abstract}
This paper explains and demonstrates how to manage personal idle money under the inflationary economic environment.First,we research the power of interest and time and conclude the importance of investment,a way of making money.Then we investigate and compare the real estate,stocks, MMF ,bonds and some P2P platform.Finally,we advise different people to invest different but most suitable financial products.
\end{abstract}

\section{Introduction}

“Time is money."This a famous quote about the importance of time in our daily life.From the financial prospective,this old saying is a truth.It is possible to make your fortune increase from one million to two million in a very limited time.For example,James Simons, the king of quantitative investment,has created the miracle that his funds gained $34 \%$ annual investment return on average.This return rate exceeds $21.45 \%$ in Berkshire Hathaway.If we have one million initial funds with $25 \%$ annual return rate,our worth will increase to two million only in three years.

Think that you have one million now(most families can satisfy this demand), what will you do?Some may argue that he will travel around the world,go shopping, try delicious foods and so on.Some are slightly sensible and suggest that he will put these idle money into commercial bank or buy money market fund(MMF) and then charge interest.Exchange market is called high-end market and a few professionals take part in it.Most people have never touched foreign currency,let alone invested in it.Financial derivatives are as well.So we don't discuss exchange market, futures or options in this paper.However,what is the best way to increase value? If we take inflation rate into account,whether we gain net interest or not?Therefore,this paper want to research some common investment methods to find the best way while balancing risks and profits.

\section{Literature References}

With the heat of the finance and stock market,many scholars has researched similar outlines.Xu Heng ,Shen Qianqian and Wang Xiaohua researched current investment situation in China and proposed some suggestions[1].Zhang Minli and Yang Wenpo applied fuzzy comprehensive evaluation method to research real estate investment,a high-risk and high returned of economic activity[2].Carmen Keller and Michael Siegrist researched the stock investment from the psychology prospective[3].Yang Yucheng researched the factors,including Shibor and currency supply,that affected the return of internet MMF.Then he put forward some suggestions on how to make investment decision[4].Gilles Sanfilippo compared the relative performance of stocks with bonds and concluded that an investor should avoid bonds in the long run[5].Yin Shaoqing took lianjia finance for example and explored the risk of P2P finance and problem of its development.At last,she put forward some detailed suggestion to companies,regulators,and investors to help the health development of P2P finance [6].However,there are few papers investigate real estate,stocks, MMF,bonds and a newly method-P2P platform.So this research focus on these common investment ways and want to find the best way when balancing incomes and risks. 


\section{The charming of time value}

Time value is related to opportunity cost.In economy,resources are limited. Opportunity cost equals to the most value you might have obtained but you abandoned when you chose to consume the resource do one thing. In this way,bank will pay you interest if you save money in your accounts, which you could have put to other places.Stocks,bonds and funds are as well.The interest rate depends on the corresponding risky.Actually,the charming of time value comes from the interest. Compound interest,different from simple interest,means that you can get interest's interest next year. The formula of compound interest is $F V=P V^{*}\left(1+r^{n}\right)$. while the simple interest is $F V=P V^{*}(1+n r)$. Here is the comparison of the single interest and compound interest as following(if initial funds is 100,000 dollars and annual interest rate is $5 \%$ or $10 \%)$ :

Table 1 Two Interest rate methods comparing

\begin{tabular}{lcccc}
\hline & \multicolumn{3}{c}{$5 \%$} & \multicolumn{2}{c}{$10 \%$} \\
\cline { 2 - 5 } & Single interest & Compound interest & Single interest & Compound interest \\
\hline Initial Funds & 100,000 & 100,000 & 100,000 & 100,000 \\
After 1 year & 105,000 & 105,000 & 110,000 & 110,000 \\
After 2 years & 110,000 & 110,250 & 120,000 & 121,000 \\
After 3 years & 115,000 & $115,762.5$ & 130,000 & 133,100 \\
After 5 years & 120,000 & $127,628.16$ & 140,000 & 161,051 \\
After 10 years & 125,000 & $162,889.46$ & 150,000 & $205,546.42$ \\
After 20 years & 130,000 & $265,329.77$ & 160,000 & $334,813.46$ \\
After 30 years & 135,000 & $432,194.24$ & 170,000 & $545,375.85$ \\
After 50 years & 140,000 & $1,146,739.98$ & 180,000 & $1,447,044.49$ \\
\hline
\end{tabular}

The above data shows the remarkable difference between compound interest and simple interest,especially after longer time.After 20 years,the funds under compound interest has increased to 265329.77,about two times more than the single interest.Then compared $5 \%$ with $10 \%$,the difference rates between single and compound are same.There is no debit that the increase rate of $10 \%$ is higher.It is similar to uniform and accelerated motion in physics.Single interest likes uniform motion, while compound interest likes accelerated motion(free fall).So we should invest rather than saving to make more money,but choosing which investment tools is important.

\section{The comparison of common investment tools}

We choose common investment tools,real estate,stocks, MMF ,bonds,and a newly method-P2P platform,to explore which is the best way.With the interest rate climbing up,the risk index is also increased.High return rate always appeals people to try and hope for high profits.Many said that they would withdraw their money to avoid loss after obtaining considerable income,but they didn't do as plan .Because we are greedy and hope for another pie falling,or we want to wait for loss made up.We can always hear that $90 \%$ of people will not gain income from stock market.However,we still wait for the lucky pie to fall on our heads.

\subsection{Real estate.}

Since 2008,the price of house has extremely been rising,especially for Shanghai and Beijing.Since a lot of people gained a great profit through buying in low price and selling in high price,more and more people joined.Finally,housing price became unbelievably high and most money flew into real estate market,rather than manufacturing,which led to bad economic circumstance.However,it is hard to change due to our traditional thoughts that we must need a house when wedding.Some buy a house to sell,rent,or for their kids.As for risk,real estate needs great amount of capital and its liquidity is not 
very well.So if price decreases,you will loss a lot.Therefore, if you have enough idle money,courage and you have a boy, putting money into real estate market may suit you.

\subsection{Capital Market.}

Stock market is a heat invest place recently.Take Guizhou Maotai for example.Its stock price is the highest in China, which is even approaching 800.However,it was no more than 400 at the same time last year,which means it doubles in a year.When calculating the interest rate,it is far more than bank deposit.If we also consider the inflation when it comes to bank deposit,our real value is decreasing.So we all choose to invest other financial products though they have risks to a degree.But if you choose to buy stocks,you need to have good psychological quality and learn some related knowledge.We loss rather than gaining owing to our greedy desire most of time.

Bonds contain corporate bonds,financial bonds, and government bonds.Different bonds correspond different internet rate and risk.Most of bonds need considerable principal and other demands, we can not direct invest bonds as an individual.We can buy government bonds to preserve value.

\subsection{Money Market.}

MMF is always connected to P2P platform,like yuebao in alipay.It is steady and gradually replace the bank deposit.Since bank deposit rate is lower than inflation rate and MMF has almost no risk,more importantly,related financial knowledge is widespread,more and more people tend to buy MMF.Then many internet finance companies are set up,and release some low risk regular financial products, which is different from MMF.MMF is a kind of fund that put collected money to monetary market,such as national debt.Most newly internet financial products have slightly higher interest rate but may have potential risks.MMF is a good choice if you are not good at investment and can't bear to loss principal.

\section{Summary}

To sum up,money has time value.If we don't invest idle money,it will depreciate.More importantly,we can get interest based on previous interest and principal.With more and more financial products released,we should balance profit and risk and learn to tell them.Through exploring five common financial tools,we advise most people to invest MMF or government bonds, which are safe and steady.And if you are a professional in money management and can bear your capital up and down,you can choose stock market.As for real estate,house is where people live and should not become a financial tool.Otherwise,there will flow more money into this market,and effect real economy development.P2P finance is immature and still at the starting stage,when we consider to invest it,we should make an in-depth investigation to find out whether it has potential risks. We suggest people not to invest small P2P credit company, which may run away with your money.It means that you also need to investigate the company background before investment.Additionally, it is more safe to buy famous company's products,like Jingdong , Baidu,or Tengxun.

All in all,remember that “don't put all eggs into a basket”. The most reasonable and safest way is to balance your investment rate between different tools.As an individual not a professional,we argue that MMF is more suitable in all "baskets". And we can learn some financial knowledge to guide our investment as investment is an activity throughout our life.

\section{References}

[1]. Xu Heng ,Shen Qianqian,Wang Xiaohua.The Current Situation, Problems and Countermeasures of Chinese Residents' Personal Finances[J].China Market,2017(16):57-58.

[2]. Zhang ML(Zhang Minli),Yang Wp(Yang Wenpo). Fuzzy Comprehensive Evaluation Method Applied in the Real Estate Investment Risks Research[J]. Physics Procedia,2012,24. 
[3]. Carmen Keller,Michael Siegrist. Investing in stocks: The influence of financial risk attitude and values-related money and stock market attitudes[J]. Journal of Economic Psychology,2006,27(2).

[4]. Yang Yucheng.Research on the Influencing Factors of the Yield of Internet MMF' Financial Products[J].Zhejiang Finance,2017(11):10-16.

[5]. Gilles Sanfilippo. Stocks, bonds and the investment horizon: a test of time diversification on the French market[J]. Quantitative Finance,2003,3(4).

[6]. Yin Shaoqing:Research on the Development of P2P Finance in Internet Finance(Master, Capital University of Economics and Business, China,2016) 